\title{
Saber, poder y matrimonio: \\ Ritualización de la práctica y signos de la dominación
}

\section{María Cecilia Colombani}

Universidad de Morón

\section{Introducción}

El propósito del presente trabajo consiste en problematizar la dimensión del matrimonio como espacio político y práctica institucionalizada; la misma aparece cargada de una fuerte ritualización, que ubica al matrimonio en un registro de peculiar observación dentro de la historia de Occidente, en el marco de las relaciones de poder, teniendo en cuenta que ha constituido un hito fundamental en el marco de la construcción de subjetividades.

Nuestra propuesta consiste en indagar las peculiaridades de la práctica en el marco de la Grecia arcaica, recorriendo algunas aspectos que devuelve el relato mítico, como logos explicativo, a partir del cual se torna un interlocutor insoslayable a la hora de inteligir las relaciones entre los distintos elementos constitutivos de una determinada configuración histórica.

Tratar de captar las relaciones de poder-saber, ubicándonos en el suelo mítico y desandando la huella de las uniones amorosas, tales como de ellas dan cuenta ciertos matrimonios emblemáticos en el horizonte de la genealogía olímpica, nos permitirá relevar la presencia de una diosa, Artemisa, vinculada fuertemente a las prácticas matrimoniales.

Asimismo, abordaremos la problemática del matrimonio desde la dimensión reproductiva, fibra misma de la cuestión matrimonial. En este tópico, proponemos ver los juegos vinculares, entendidos como juegos de poder, que se dan al interior de la pareja, a partir de la determinación natural.

El desafío consiste en rescatar la figura femenina y la masculina al interior de un espacio sobrecargado de consideraciones y sesgado por una fuerte ritualización, que pone de relieve la importancia del mismo como usina subjetivante, inscrita en un horizonte dominado por las tensiones de poder. 
Esta es la principal búsqueda: ver en qué medida el matrimonio aparece como el topos natural destinado a la consolidación de lo femenino y de lo masculino.

De allí que, como toda institución que constituya un pilar de la consolidación histórico-cultural, el mito, como historia significativa, verdadera y paradigmática, de cuente de ella.

\section{Matrimonios divinos: las delicias conyugales}

Ciertas bodas reales marcan las pautas de consolidación matrimonial. Constituyen, en su dimensión didáctica y ejemplar, el sentido de la práctica, al tiempo que instituyen el campo agonístico en el cual la misma se inscribe.

Recortemos nuestro corpus de trabajo. Pensemos en Zeus y sus múltiples esposas. Para ello, debemos recurrir a la Teogonía hesiódica.

El final del mito de soberanía es el inicio de nuestro atajo: "Luego que los dioses bienaventurados terminaron sus fatigas y por la fuerza decidieron con los Titanes sus privilegios, ya entonces por indicación de Gea animaron a Zeus Olimpico de amplia mirada para que reinara y fuera soberano de los Inmortales. $Y$ él les distribuyó bien las dignidades" (Hesíodo, Teogonía, 882-886). La cita nos remite al punto de inicio del tratamiento hesiódico de las uniones del Crónida. Concluida la ordenación cósmica, tras las largas luchas que ubican el reinado de Zeus como producto de un dispositivo agonístico narrado, precisamente, por el mito de soberanía, el padre de todos los dioses y los hombres tiene varios matrimonios, como forma quizás de consolidación del orden adquirido.

Podemos pensar que, el matrimonio y sus frutos aparecen como una necesidad a la hora de robustecer el modelo olímpico, modelo que ha devuelto las peripecias políticas que la instauración del poder implica. No hay orden sin pólemos y no hay continuidad política del orden sin uniones que lo consoliden.

Metis, una de las Oceánides, hija de Océano y Tetis, parece ser la primera dama elegida. Cuenta Hesíodo que "Zeus rey de dioses tomó como primera esposa a Metis, la más sabia de los dioses y hombres mortales" (Hesíodo, Teogonía, 887-888). Extraña cualidad de Metis, la prudencia, necesaria para gobernar el Cosmos; en ella la cualidad aparece en grado superlativo, lo cual no es poca cosa a la hora de relevar los juegos de poder. Zeus no duda en apropiarse de su cualidad, para que nadie pueda sobrepasar su propia sabiduría. El poder es solidario del saber y las relaciones entre saber-poder entrañan juegos de acción complejos. La propia acción de Zeus así lo indica. El rey de 
dioses y hombres despliega su estrategia política y traga a su esposa por indicación de Gea y de Urano, cuando faltaba poco para que naciera Atenea, la hija concebida.

Notable acontecimiento que ubica a Zeus en un lugar particular: deseando un elemento de la naturaleza femenina; en realidad, desea apropiarse de un don de su esposa, inaugurando con su actitud un juego de poder que supone, de algún modo, el desconocimiento del otro, como forma de neutralización de su poder-saber.

Tragarla es literalmente el modo de usurpar un elemento femenino necesario para la consolidación del reinado del Olímpico. Zeus vigila su poder, teme que le sea arrebatado, como también lo temieron sus antecesores, Urano y Cronos, ya que estaba determinado que, de esa unión, dos vástagos poderosos nacerían y constituirían una amenaza para su padre. Sin duda, en el marco de las tensiones por el poder, la estrategia es un elemento capital: Metis, engañada con ladinas palabras y retenida en el vientre de Zeus para neutralizar su propio poder, sería la encargada de revelarle siempre lo bueno y lo malo.

Su astucia, deglutida por el soberano, es una pequeña joyita al interior de la urdimbre política y resulta funcional al poder real. La resolución de la estrategia es singular y paradigmática desde una lectura política, en términos de supremacía masculina: una hija, sin madre, salida de de la frente de su padre, nacerá: Atenea, su querida hija, quien estuviera, en su momento, en el seno de Metis, arrebatado por el padre.

Como sabemos, Atenea sale un día de la cabeza de Zeus; en efecto, "él, de su cabeza, dio a luz a Atenea de ojos glaucos, terrible, belicosa, conductoras de ejércitos, invencible y augusta, a la que encantan los tumultos, guerras $y$ batallas" (Hesíodo, Teogonía, 924-927). El otro vástago, ya que eran dos los hijos esperados, nunca conoció la luz. Zeus no sólo arrebata la astucia de Metis, sino también el poder de alumbramiento, rasgo femenino por excelencia. De algún modo él pare a Atenea, ya que ésta nace de su frente, en un acto de partenogénesis. Nuevo deseo de rasgos femeninos y nuevo desplazamiento de un rey que parece demarcarse en la circulación de su deseo. 


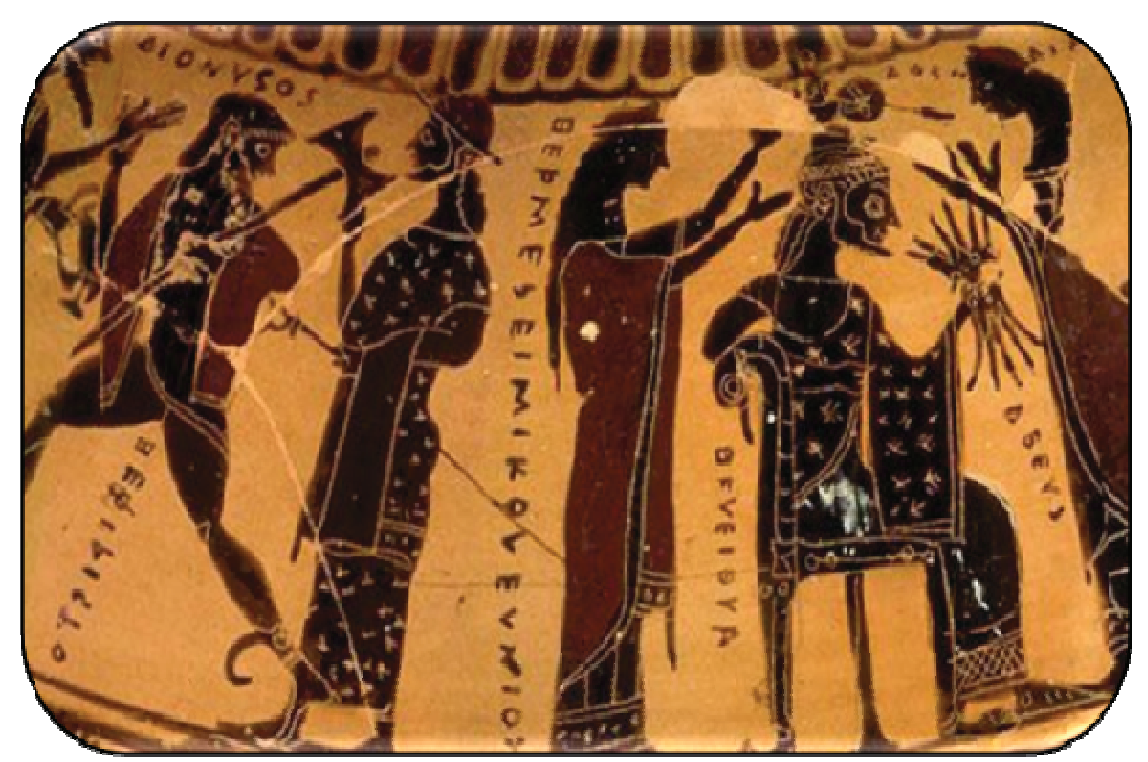

De un segundo matrimonio nacen ciertos vástagos capaces de contribuir al orden, difícilmente conseguido. Narra Hesíodo: "En segundo lugar, se llevó a la brillante Temis que parió a las Horas, Eunomia, Dike y la floreciente Eirene, las cuales protegen las cosechas de los hombres mortales, y a las Moiras, a quienes el prudente Zeus otorgó la mayor distinción, a Cloto, Láquesis y Átropo, que conceden a los hombres mortales el ser felices y desagraciados". (Hesíodo, Teogonía, 900-905). Analicemos brevemente las delicias de este matrimonio, siempre en clave política, esto es, en el marco de nuestro proyecto de lectura: ver cómo el matrimonio resulta una práctica funcional al orden instituido.

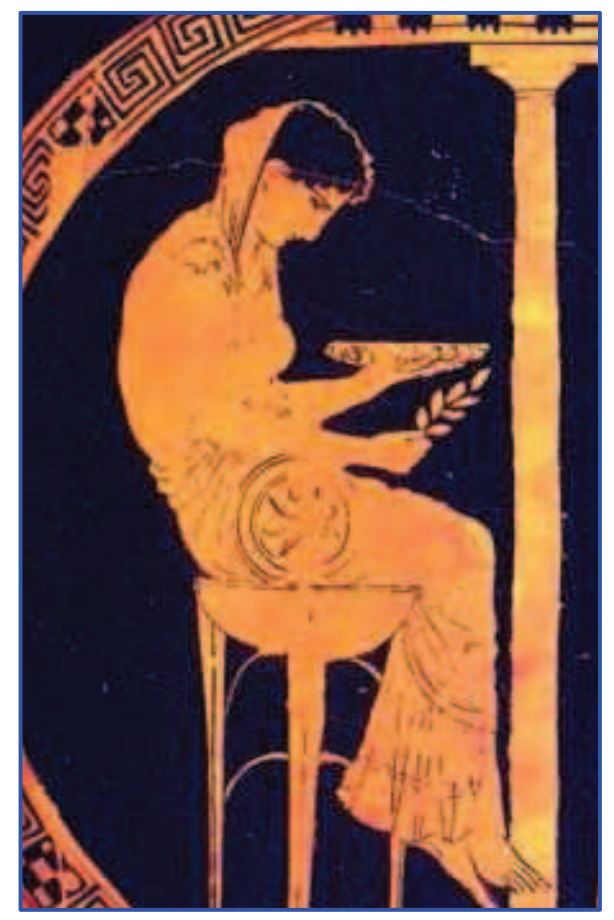

La dulce esposa, Temis, representa la justicia primordial, lo valedero y lo esencial. Continuando con las líneas de un linaje luminoso, las hijas, habidas en el matrimonio, representan valores fundamentales para la consolidación de todo orden. Colectivo femenino de rasgo positivo y luminoso que con su acción posibilita las relaciones entre los hombres, haciendo prósperos los trabajos de los mortales.

Sus hermanas no son menos importantes: Eunomía, "Buen orden”, parece representar arquetípicamente un elemento capital en la nueva y triunfante organización cósmica. Dike, Justicia, resulta la 
personificación del elemento sin el cual no hay organización posible, ya que el orden es en sí mismo justo. Eirene, Paz, resulta, quizás, la imagen fundacional de la posibilidad de continuidad del orden, a partir de su reinado frente a la discordia. No termina allí la descendencia; finalmente las Moiras y las Parcas, divinidades sombrías, emparentadas con la muerte, completan el círculo familiar.

Retornemos a las Horas. Antes de su aparición en la teogonía hesiódica, las Horas aparecen ya en Ilíada como guardianas de las puertas del Olimpo, una puerta que se abre y se cierra para juntar o dispersar las nubes. Son divinidades sonrientes, que presiden todo aquello que llega a su hora, como un fruto maduro que cae del árbol en el momento preciso. Allí están, en las bodas de Tetis y Peleo; presiden también el crecimiento de la vegetación, porque simbolizan fenómenos naturales como el brotar de la vegetación cuando llega la estación y suelen, como las Gracias, de quienes se hallan muy próximas por características afines, aparecer danzando. Presiden el nacimiento y el casamiento, pero no la muerte porque están siempre presentes en momentos dichosos. Son ellas quienes coronan a Pandora con flores, según refiere Hesíodo en estos términos: "Las divinas Gracias y la augusta Persuasión colocaron en su cuello dorados collares y las Horas de hermosos cabellos la coronaron con flores de primavera". (Hesíodo, Trabajos y Días, 75).

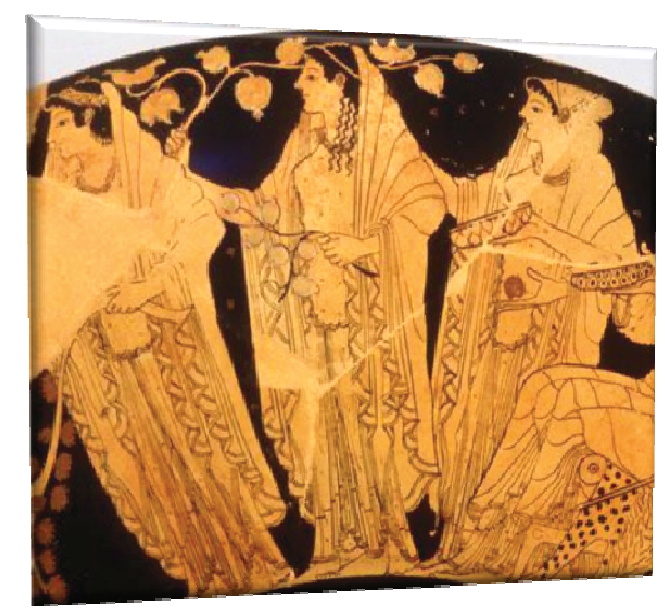

La fecundidad de Zeus lo lleva a un tercer matrimonio y a una nueva generación de vástagos, siempre funcionales a la ordenación del kosmos. "Eurinome, hija de Océano, de encantadora belleza, le dio las tres Gracias de hermosas mejillas, Aglaya, Eufrósine y la deliciosa Talía". (Hesíodo, Teogonía, 908-910). Según Hesíodo su morada en el Olimpo está próxima de la morada de las nueve Musas, también hijas de Zeus en un próximo matrimonio que analizaremos. El culto de las Gracias es de muy 
antigua data, precisamente en el antiguo Orcómeno, Beocia. También ellas favorecen el desarrollo de la vegetación, y, emparentadas por ende con la fecundidad, se las veneraba para lograr la abundancia de las cosechas. Sin ellas no se conoce nada amable y bello, según refiere Teócrito. Se las representa habitualmente bailando, con ritmo sutil y gracioso en los movimientos, en el andar, en los gestos y actitudes, que las devuelve como símbolos mismos de la armonía. Tal como las pinta Hesíodo, "De sus párpados brota el amor que afloja los miembros cuando miran y bellas son las miradas que lanzan bajo sus cejas". (Hesíodo, Teogonía, 910-913). Los matrimonios se suceden y parecen, hasta el momento, generar un tipo de descendencia que se vincula fuertemente con la organización luminosa y positiva del orden que Zeus ha instituido.

Una cuarta unión lleva al Soberano al lecho de Deméter, nutricia de muchos. Se trata de una divinidad agraria, complementaria de otro vástago, Zeus, de muy particulares características. Si Dioniso está asociado al vino, al elemento líquido, Deméter lo está al pan. Es la Madre Tierra, quien no debe ser confundida con Gea, la tierra primordial, indiferenciada, esposa de Urano, deidad de los primeros ciclos genealógicos. Diosa del trigo, símbolo de la maternidad, de los dolores que ella supone, a partir de lo que será la búsqueda de su hija. Quizás por eso se trata de una divinidad cercana, más humana que otras. Zeus subió a su lecho y juntos concibieron a Perséfone, que luego Zeus concediera a Hades, quien la arrebatara de los brazos de su madre.

En efecto, Zeus concede su hija a su hermano, Hades, el oscuro rey de los muertos, que rapta a Perséfone, quien, según el Himno Homérico, jugaba con las Oceánides, mientras recogía flores: "Comienzo por cantar a Deméter de hermosa cabellera, la augusta diosa; a ella y a su hija de esbeltos tobillos, a la que raptó Aidoneo (y lo permitió Zeus tonante, cuya voz se oye desde lejos), cuando, apartada de Deméter la del arma de oro, de hermosos frutos, jugaba con las muchachas de ajustado regazo, hijas de Océano, y recogía flores: rosas, azafrán y hermosas violetas, en el tierno prado, y también gladiolos, y jacinto, asi como el narciso, que, como señuelo, hizo brotar para la muchacha de suave tez de flor la Tierra, según los deseos de Zeus, por halagar al que a muchos acoge". (Himno Homérico a Deméter, 1-10). 
El Himno nos pone en pista. Esta unión trae un complejo escenario de poderes en pugna, que plasman, una vez más, un despliegue conflictivo de las relaciones entre dioses.

Para complacer los deseos de Hades, aquel que a muchos acoge, y siempre con el consentimiento de Zeus, Gea hace brotar de la tierra un narciso de peculiar belleza, "flor de prodigioso brillo, asombro entonces de ver para todos, tanto dioses inmortales como hombres mortales" (Himno Homérico a Deméter, 1012). Perséfone no puede resistirse al deseo de apropiarse de la flor y cuando se dispone a poseerlo, la tierra se entreabre y Hades aparece en su carro y rapta a la joven. En efecto, "se abrió la tierra de anchos caminos en la llanura de Nisa y de alli surgió con impetu, con sus yeguas inmortales, el Soberano que a muchos acoge, el hijo de Crono de múltiples advecciones. Se apoderó de ella, mal de su grado, y se la llevaba entre lamentos sobre su áureo carro". (Himno Homérico a Deméter, 17-20).

Deméter conoce el dolor maternal del rapto de su hija y ésta añora volver a reencontrarse con su madre, que había oído el eco del grito de su hija, mientras desaparecía y gemía por ayuda. Este es el mayor dolor de una madre que inicia un largo itinerario buscando afanosamente a su hija, recorriendo toda la tierra, padeciendo penurias hasta que encuentra a Hécate, una tierna diosa, que le cuenta que ella oyó el grito de Perséfone pidiendo ayuda. "Sólo la hija de Perses, la de ingenuos sentimientos, la oyó desde su antro: Hécate, la de brillante tocado (y asimismo el soberano Sol, el ilustre hijo de Hiparión), cuando la muchacha invocaba a su padre, el Crónida". (Himno Homérico a Deméter, 24-27). Finalmente es el Sol, quien le cuenta la verdad, ya que grande es el respeto que dice tener por la diosa y al verla "afligida como estás por tu hija de esbeltos tobillos" (77).

El relato está devolviendo el dolor de una madre, símbolo universal del sufrimiento femenino, al tiempo que describe las relaciones de poder que se juegan entre la diosa y Zeus como modo de recuperar lo arrebatado. Nuevo relato del arrebato, el Himno nos devuelve las estrategias de Deméter para recuperar a su hija. Sabemos que su dolor conmueve hasta las entrañas al soberano Sol y así le relata el rapto a manos de Hades, con el consentimiento 
de Zeus, su esposo. Nada tienen en común el reino de la luz y el reino sombrío de los muertos; constituyen topoi heterogéneos, impermeables e intransitables, que ponen a Perséfone en el más genuino lugar de la muerte.

Deméter simboliza la imagen más real del dolor maternal. El Himno es elocuente cuando relata el peregrinaje de la madre por su hija, antes de la noticia: "Desde entonces, durante nueve días anduvo errante por la tierra, llevando en sus manos antorchas encendidas. Y ya no se nutria con la ambrosía ni el néctar dulce de beber, presa de la aflicción". (Himno Homérico a Deméter, 24-27). El odio de Deméter hacia Zeus la lleva a abandonar el Olimpo y a refugiarse entre los hombres. Su dolor de madre y la furia de esposa la conducen a dejar su lugar junto a los Olímpicos y acercarse a los hombres, emparentada con ellos en el dolor que los caracteriza. En efecto, "a ella un dolor más cruel y más perro le llegó al ánimo. Irritada contra el Cronión, amontonador de nubarrones, tras apartarse en seguida de la asamblea de los dioses y del grande Olimpo, marchó a las ciudades de los hombres y a sus pingues cultivos, desfigurando por mucho tiempo su aspecto". (Himno Homérico a Deméter, 90-95). La diosa no duda en abandonar su topos olímpico, atravesada por su pena. Deméter representa el dolor maternal por excelencia, así como la búsqueda desesperada de una madre que le han arrebatado su don más prestigioso: un hijo. El mito funda un modelo universal de comportamiento.

Pero no termina allí la gesta fundacional. Deméter encarna el amor maternal, el cuidado que una madre prodiga a su hijo, en entrega generosa. Ya entre los hombres, en tierra eleusina y tomando la fisonomía de una vieja, la diosa se ocupa del hijo del rey Celeo, de Eleusis, el pequeño Demofonte.

En principio, "se sentó a la vera del camino, afligida en su corazón, en el pozo Partenio (...) y, con el aspecto de una anciana muy vieja, que está ya lejos del parto y de los dones de Afrodita amante de las coronas, como son las nodrizas de los hijos de los reyes que dictan sentencias, y las despenseras en sus moradas llenas de eco". (Himno Homérico a Deméter, 98-104). Allí se encuentra con las jóvenes hijas del rey, Calícide, Clisídice, Demo y Calítoe, quienes, apiadadas de la anciana, aunque sin reconocerla, se disponen a ayudarla. Deméter, siempre ocultando su origen divino, les pregunta "a casa de quién podría ir, sea de un 
varón, sea de una mujer, donde pudiera realizar para ellos, bien dispuesta, cuantas tareas son propias de una mujer de mi edad?' (138-140). Por supuesto que el himno permite entrever marcas de género en lo que se refiere a las tareas femeninas: ser una buena nodriza, cuidar la casa, tender los lechos de las alcobas, instruir a las mujeres en sus labores. Breve recorrido en boca de Deméter de lo que se espera de una mujer madura, territorializada al oikos y afectada a actividades que sólo corresponden al universo femenino. Es más, una de ellas es la asignada a la diosa en casa del rey Céleo.

Las jóvenes llevan a la diosa a la morada de su padre y le comentan todo a su madre Metanira, "de ajustada cintura" para ver si la invita a quedarse con ellos y no seguir deambulando. El lugar es el apropiado a una mujer ya que, "Un hijo de antigua alcurnia se cría en su bien construida morada, tardio, muy deseado y cariñosamente recibido". (Himno Homérico a Deméter, 165-168). Este es el destino de Deméter en tierra eleusina. Cría al niño, constituyendo un nodriza perfecta, envidia de las femeniles mujeres. Deméter acepta y se compromete a criarlo y cuidarlo para evitarle todo maleficio. La historia continúa e incluso Deméter se reencuentra con su adorada hija Perséfone, quien, por indicación de Zeus pasa buena parte del año entre los dioses y un tercio con Hades, en su sombría mansión. Fue Zeus quien ordenó convencer a Hades con suaves palabras para luego traer a Perséfone "desde la nebulosa tiniebla hasta la luz, entre los dioses, a fin de que su madre, al verla con sus ojos, cesara en su cólera". (Himno Homérico a Deméter, 336-340). Por supuesto que la cólera de Deméter significa el castigo que cae sobre los hombres y sus cosechas. Deméter con su poder tensiona los juegos de poder con su esposo, Zeus, quien decide restituirle a su hija.

El largo apartado precedente supone el interés de mostrar ciertas marcas de género en la figura de Deméter, básicamente resumidas en los siguientes ítems: su amor de madre, su dolor de madre, su abnegación y renuncia por la búsqueda de su hija, la capacidad de nutrir y criar, la lucha de la que una madre es capaz si le arrebatan lo más preciado. Este matrimonio real no ha hecho sino nutrir los valores y comportamientos esperables de una esposa, en este caso, encolerizada. 
A su vez, el apartado nos permitió acercarnos a los juegos de poderes que se dan en el escenario: Zeus- Deméter, Zeus- Hades, Deméter- Hades. Juegos dinámicos de un tipo de poder funcional y estratégico.

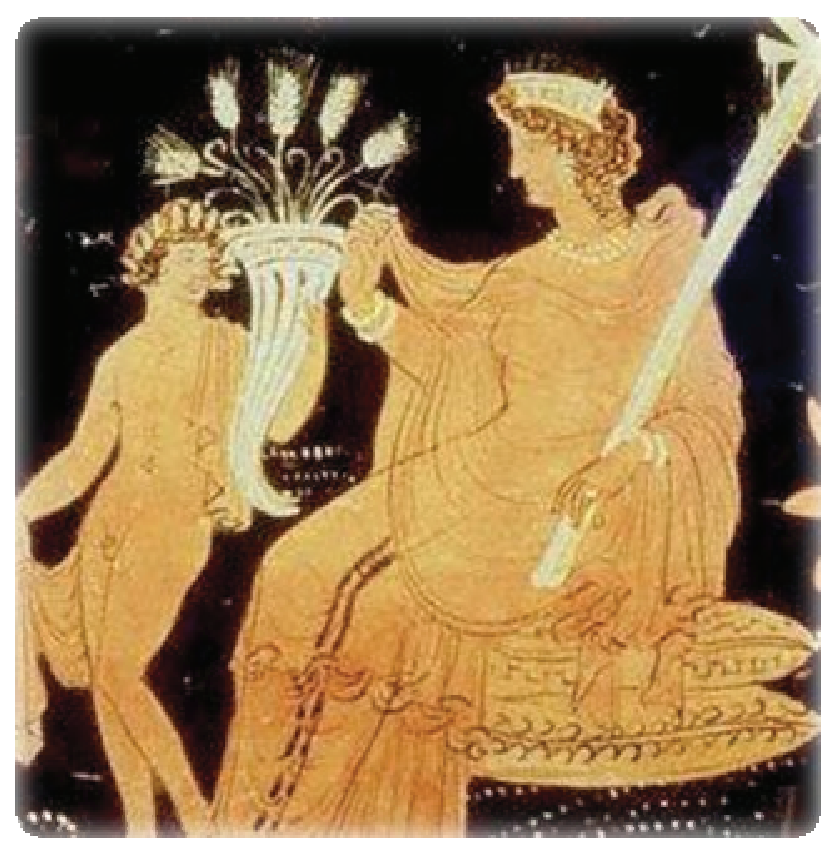

Un nuevo matrimonio merece alguna atención. El testimonio vuelve a ofrecerlo Hesíodo, cuando da cuenta de ello en estos términos: "También hizo el amor a Mnemosyne de hermosos cabellos $y$ de ella nacieron las nueve Musas de dorada frente a las que encantan las fiestas y el placer del canto" (Hesíodo, Teogonía, 915-918). Una vez más el elemento femenino es doblemente

significativo, la esposa y las hijas habidas en matrimonio. Figuras luminosas, colectivo femenino de poder marcado, desplegando la Memoria y la Palabra como elementos solidarios de la constitución del pensamiento arcaico.

Mnemosyne es la señora de las colinas de Eleuter, quien amancebada con el Padre Crónida alumbró a las nueve Musas en Pieria. El verbo es elocuente y habla, por supuesto, de contacto amoroso, lo cual permite la reproducción sexuada. Nueve noches se unió con la diosa el prudente Zeus, subiendo al lecho sagrado y alejado de los Inmortales, lo cual supone un desplazamiento del padre de dioses y hombres en busca de su esposa. Cuando el ciclo de las estaciones hubo culminado, "nueve jóvenes de iguales pensamientos, interesadas sólo por el canto y con un corazón exento de dolores en su pecho, dio a luz aquélla, cerca de la más alta cumbre del nevado Olimpo". (Hesíodo, Teogonía, 60-63). La esposa es una señora esposa, una primerísima dama que ha brindado a su esposo esas hijas deliciosas que sabrán honrarlo con su canto. 
La señora de Eleuter es la Memoria sacralizada, una omnisciencia de carácter adivinatorio, la única que sabe lo que fue, lo que es y lo que será, según Marcel Detienne. Una memoria que nada tiene que ver con nuestra memoria humana, como facultad psicológica.

Las hijas no se quedan atrás en brillo y esplendor. Son las delicadas y bienhabladas hijas de Zeus, siempre dispuestas a alabar al padre con sus bellos cantos, disipando las preocupaciones y los dolores de pecho. Delicadeza, dulzura, ternura, disposición a la alabanza parecen reforzar las cualidades de género. Serán ellas las que faciliten al recitador el recuerdo del poema, ya que, como sabemos, la inspiración se concibe en la antigüedad como un enthusiasmos, una posesión por parte de la divinidad que supera la inteligencia humana por doquier. Así son estas criaturas nacidas en Pieria, cerca del Olimpo, en Tesalia. Emparentada con Apolo, el "conductor de las Musas", así las presenta el Himno Homérico dedicado a su honor: "Debo comenzar por las Musas, por Apolo y por Zeus. Pues merced a las Musas y a Apolo, el Certero Flechador, existen sobre la tierra los aedos y los citaristas. $Y$ merced a Zeus, los reyes". (Himno Homérico a las Musas y a Apolo, 1-5).

Son las bienhabladas hijas las que con voz amable y deliciosa cantan y celebran las normas y las costumbres sabias de los dioses. Aparece así una cierta funcionalidad de estas hijas maravillosas en lo que concierne a la organización cósmica, jugando una función política en la continuidad de la Memoria. Clío, Melpómene, Talía, Terpsícore, Érato, Polimnia, Urania, Euterpe y Calíope resultan imprescindibles a su amado padre, a quien no dejan de alabar; imprescindibles también para la función poética, sostenedora del orden y la justicia cósmica, ya que, como dijimos, sin ellas, no hay canto poético. Así lo expresa Homero: "Decidme ahora, Musas, dueñas de olimpicas moradas, pues vosotras sois diosas, estáis presentes y sabéis todo, mientras que nosotros sólo oimos la fama y no sabemos nada, quiénes eran los principes y los caudillos de los dánaos". (Homero, Ilíada, II, 483-486). Saber y poder. Tal parece ser el rasgo identitario de las jóvenes deidades.

Dignas hijas de una madre que lo sabe todo; figuras femeninas necesarias y funcionales a los designios del Padre de hombres y dioses, las 
Musas resultan aliadas incondicionales de su padre en su gesta fundacional del orden, que tanto ha costado instaurar.

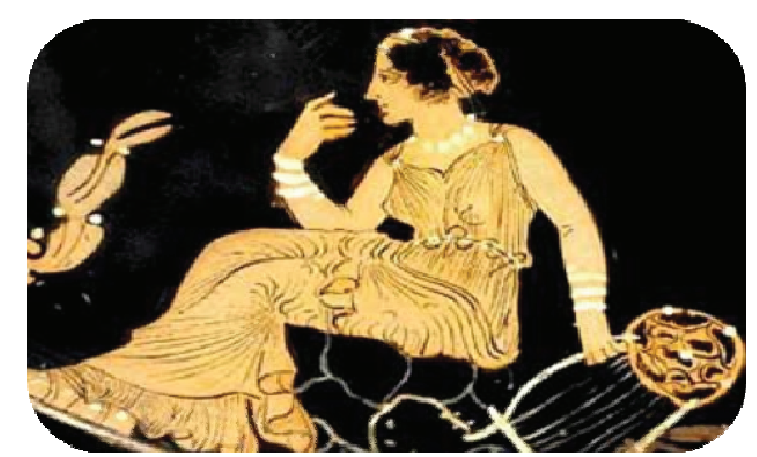

Un nuevo contacto amoroso pone a Zeus en relación con Leto, una nueva esposa. Dos vástagos brillantes nacerán de ese matrimonio divino, Apolo y Artemisa; dos hijos funcionales a la organización porque representan valores y comportamientos indispensables para la construcción de un modelo cósmico. Artemisa merecería un apartado especial por sus vinculaciones con el dispositivo matrimonial, que excede el presente trabajo.

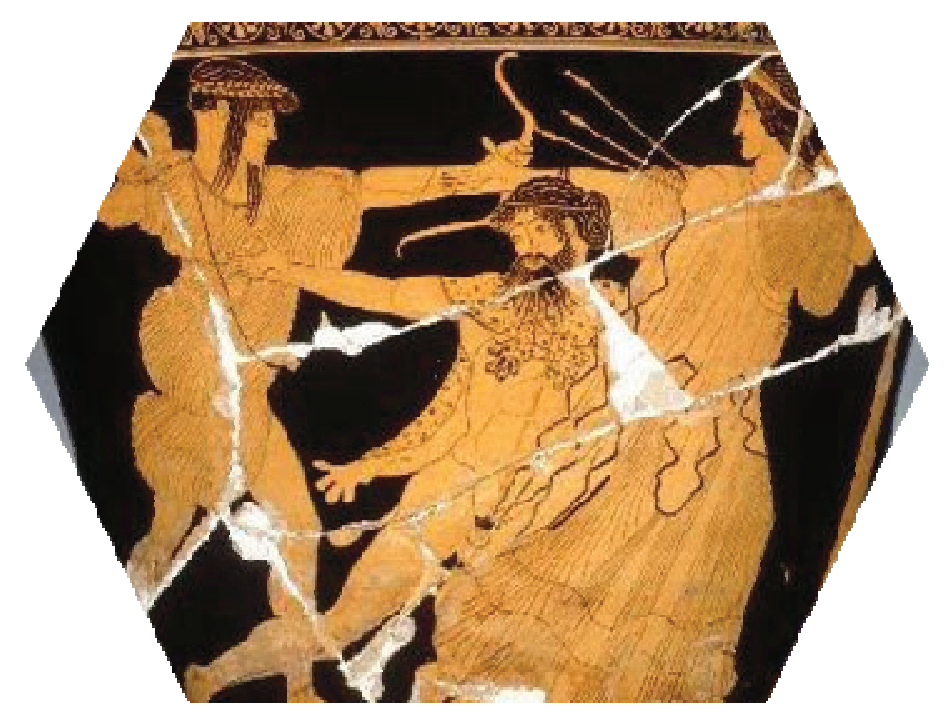

Sólo algunos aspectos de ese otro hijo superlativo al interior de la economía olímpica. Apolo parece reunir en su figura, y en la economía general de la narrativa oracular que preside, dos topoi estrechamente vinculados entre sí. Por un lado, la dimensión de legislador moral y, por otro, la dimensión del ejercicio de un poder, a partir, precisamente, del conocimiento del fundamento.

La acción de legislar, nomotheteo, implica al mismo tiempo, ordenar, determinar. Es la función de quien ostenta la arkhe para abrir el juego de la obediencia moral. Así, quien legisla, tiene la función de mandar, arkhein, de ser el primero, guiar, ser jefe, presidir, gobernar, dominar. Parece bordarse míticamente una metáfora política que sienta las bases de futuras alianzas entre ética y política, quela ciudad clásica sabrá desplegar en su constitución éticopolítica. 
Apolo presenta otro rasgo funcional a la consolidación del dispositivo político, ya que parece ocupar un papel dominante en el marco de constitución de las poleis griegas. Apolo, el legislador, organiza fundamentalmente los espacios, respondiendo a su figura de músico, de protector de fronteras, de pastor. La fundación de una ciudad, con su imperativo de proporción y medida no dista de la narrativa musical, subtenida por las mismas nociones.

Apolo es, como ya anticipamos a propósito de las Musas, un conductor. No sólo organiza el kosmos político, sino también el universo moral. En realidad, constituye un mismo acto fundacional y arquetípico porque sin medida y sin ley no hay organización alguna.

Apolo está presente en la polis como aquellas huellas indelebles que los nuevos giros intelectuales no logran borrar, como aquellas marcas que los avatares del pensamiento no pueden sepultar. El espíritu apolíneo marca rumbos, delinea geografías, planea esquemas estratégicos, porque la ética no es otra cosa que una gran batalla por el ejercicio de la arkhe. Desde esta lectura, la ética se inscribe en una dimensión agonística, en el modelo de la batalla perpetua para devenir un sujeto amo de sí, un sujeto soberano, responsable de sus actos. Apolo es un cartógrafo que dibuja mapas e invita a recorrer un methodos; aquel camino que delinea el mapa del sujeto ético. Apolo es un pastor que conoce el camino y recomienda su tránsito.

Apolo mismo es el nomothetes, el legislador, aquel que revisa un código, que da las leyes, que ordena y determina. Lo que determina es propiamente el límite, lo que constituye la marca de una partición, lo que despliega el campo de constitución del sujeto prudente.

En los recorridos etimológicos, conviene que atendamos al campo semántico de los términos que constituyen la díada ética en tensión: sophrosyne significa buen sentido, prudencia, cordura, sensatez, moderación, templanza, entre otras acepciones. El verbo sophronizo significa hacer a uno prudente, corregir, advertir, castigar, reducir con prudencia. En el otro extremo de la tensión, el término hybris alude a la noción de altanería, insolencia, soberbia, impetuosidad, inquietud, arrebato, ultraje, desenfreno, licencia, daño. El campo lexical del verbo hybrizo, acompañando el horizonteque venimos 
rastreando, significa vivir disolutamente, ser soberbio, comportarse de manera injusta u ofensiva, injuriar, afrentar.

Apolo es el legislador porque es aquel que impone la mesura-medida como forma de conjurar los peligros de la des-orbitancia, como pasaporte a la intemperancia.

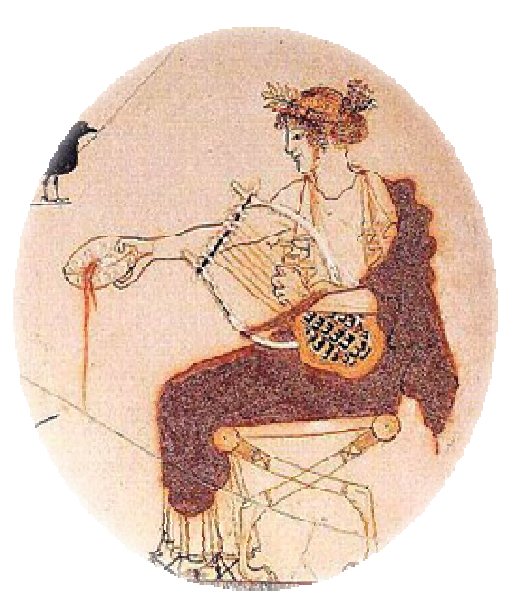

Este es el perfil de un hijo ejemplar, indispensable en la consolidación del cosmos humano, y, en tal sentido, un hijo funcional al dispositivo de organización social y política.

Conviene escuchar el Himno Homérico, no sólo como modo de saber las peripecias del nacimiento peculiar de este hijo imponente, sino también para conocer los juegos de poder que la propia Leto sostiene en su afán de parir. En principio nos informa sobre la nueva esposa de Zeus: "Leto es la única que permanece sentada junto a Zeus que se goza con el rayo. Ella es la que distiende el arco, cierra el carcaj y, tras tomar con sus manos de sus robustos hombros el arco, lo cuelga de un clavo de oro en la columna de su padre y asimismo lo lleva a sentarse en un trono" (Himno Homérico a Apolo, 5-10). Leto está feliz de haber parido "un hijo poderoso y capaz de llevar el arco". Apolo fue parido en la rocosa Delos, cuando Leto se apoyó en la gran montaña y en la altura del monte Cinto. "De uno y otro lado, el sombrio oleaje se abatía sobre la costa, a impulsos de los vientos de silbante soplo. Surgido de alli, te enseñoreas sobre los mortales todos". (Himno Homérico a Apolo, 28-30). Leto, la hija más gloriosa del titán Ceo, permaneció nueve días y nueva noches atravesada por dolores de parto, en compañía de las demás diosas, Dione, Rea, Temis, Icnea y Anfitrite, hasta que finalmente, "a Leto le sobrevino el parto y sintió el deseo de dar a luz. En torno a la palmera echó ambos brazos y apoyó las rodillas en el blando prado. Sonreía la tierra bajo ella. Salió él fuera a la luz y las diosas gritaron todas a una". (Himno Homérico a Apolo, 116-119). Algarabía olímpica ante el nacimiento de semejante criatura, hijo irreprochable y poderoso. 
Todos los cuidados que una mujer sabe impartir recibió el vástago de Zeus y Leto: las diosas lo lavaron en agua clara, lo fajaron con lino blanco, fino y nuevo y lo envolvieron con una cinta de oro. Temis le ofreció el néctar y la ambrosía ante el regocijo de Leto, que había parido a ese vástago formidable.

Artemisa, hermana del Certero y diseminadora de dardos, fue parida en Ortigia. Estrecha parece ser la relación con su hermano, tal como informa el Himno dedicado a la diosa: "Canta, Musa, a Ártemis, la hermana del Certero, la virgen diseminadora de dardos, criada a la vez que Apolo, la que, tras haber abrevado sus corceles en el Melete de espesos junquerales, impulsa raudamente su carro, todo él de oro, a través de Esmirna, hasta Claros cubierta de viñedos, donde el arco de plata, Apolo, está sentado a la espera de la certera flechadora, diseminadora de dardos". (Himno Homérico a Ártemis, IX, 1-9). Diosa virgen, de áureas saetas, cazadora y asidua a los lugares umbríos, amante de la caza, Artemisa representa valores capitales en la consolidación del espacio cívico.

Apenas un rasgo que vuelve a emparentarla con su hermano, Apolo, el del arma de oro. A su espacio se dirige, al espléndido pueblo de Delfos, "disponiendo alli el hermoso coro de las Musas y las Gracias. Tras colgar alli su elástico arco y las saetas, dirige los coros, iniciando el canto con encantador aderezo sobre su cuerpo". (Himno Homérico a Ártemis, XXVII, 15-19). Juntos celebran a Leto, su venerable madre, que pariera estos espléndidos hijos, memorables por sus hazañas.

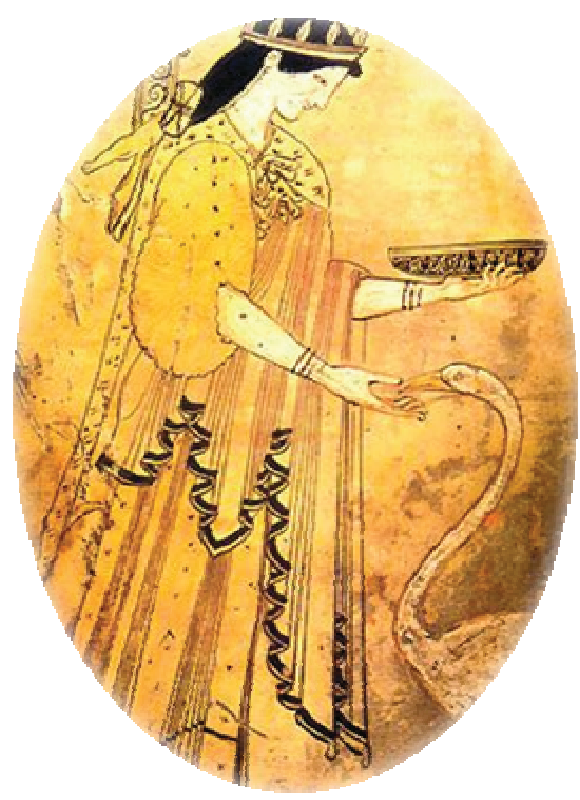

Finalmente, Zeus tomó por esposa a Hera, quien en contacto amoroso con el Crónida parió otros tres vástagos: Hebe, Ares e Ilitía. Figura fuerte junto a su esposo y hermano, a quien la une una relación complicada y tensa, de complejo juego en las relaciones de poder. En efecto, son hermanos, ya que ambos son hijos de Rea y Crono, los padres primigenios. El Himno Homérico se refiere a ella con los adjetivos y la forma habitual que registran los himnos: 
"Canto a Hera, la de áureo trono, a la que engendró Rea, a la reina inmortal, dotada de suprema hermosura, de Zeus tonante hermana y esposa, la gloriosa, a la que honran reverentes todos los bienaventurados por el vasto Olimpo, por igual que a Zeus, que se goza con el rayo". (Himno Homérico a Hera, 1-6).

Su lugar es, dentro de la economía matrimonial olímpica, singular y, sobre todo, conflictivo, a partir de los juegos de poder que entabla la pareja real. Su espíritu suele estar atravesado por la cólera y la venganza, frente a la equidad y la piedad que caracterizan a su esposo, tensionando, una vez más, las posiciones de género.

La funcionalidad vuelve a aparecer y a expresarse como necesidad en un cosmos que se tensiona y consolida a partir del despliegue de contrarios. No hay realidad que se sostenga en el universo mítico por fuera de una lógica que mantiene la lucha de contrarios como motor de constitución de lo real.

Mientras su presencia en Hesíodo es menor, señalada simplemente como la última esposa de Zeus, Homero le dedica un buen tratamiento, construyendo el modelo de esposa celosa, perseguidora de amantes e hijos ilegítimos. Su deseo de venganza la lleva a una persecución implacable de los hijos que su marido tiene con mortales. El caso más emblemático quizás sea el odio con que persigue a Dioniso, hijo de Zeus y Semele. Parecería en un punto simbolizar los avatares de la vida conyugal, su lado más oscuro y conflictivo; pero, en el universo de los dioses y en el marco de una lógica de la ambigüedad, una única mirada de la divinidad suele resultar pobre y unilateral. Hera es también la diosa venerada en Argos y Samos, donde representa una cara más luminosa y equilibrada del matrimonio, el respeto por el orden, le trabajo en silencio, la agrupación de los hijos en torno al seno familiar, y la más típica partición genérica de un esposa que atiende el oikos y un marido que combate en el exterior en el marco de las penurias que la guerra supone. Una misma divinidad tensionando modelos aparentemente antagónicos y excluyentes que la ambigüedad solidariza en una misma figura compleja.

Homero la presenta como una mujer vigorosa, capaz de hacerle frente a su marido, el más poderoso de los Inmortales. La Ilíada está llena de ejemplos al respecto, donde los juegos de poder tensionan la armonía olímpica, sobre 
todo a partir del deseo de muerte que atraviesa a Hera y sus ansias de ver destruida a Troya.

Hera y Zeus representan un ejemplo fantástico de las tensiones de poder al interior de la relación conyugal. La figura femenina resulta atípica frente a los arquetipos de género ficcionados. Esto no significa opacidad en el poder del padre de hombres y dioses, pero sí ciertos matices en las relaciones de poder y un notorio posicionamiento de Hera para hacer frente a la voluntad omnímoda de su esposo.

Es ella, sin duda, la que ostenta un registro de poder mayor al del resto de las mujeres de Zeus y al de las bellas mortales, que han despertado los deseos del Crónida.

En este terreno complejo de relaciones de poder, Leto debe huir de lado en lado hasta llegar a Delos a parir a su hijo; la cadmea Semele, hija del Rey de Tebas, es fulminada por el rayo del propio Zeus por venganza de una Hera despiadada que no cesa en su agon hasta dar con el fruto de esa unión, "el muy risueño Dioniso, un inmortal siendo ella mortal'. (Hesíodo, Teogonía, 941942).

El Himno Homérico a Apolo, ya analizado, representa un claro testimonio de este enfrentamiento que tensiona poderes, cuando presente ante la asamblea de dioses, Hera afirma: "¡Oídme todos los dioses y todas las diosas, cómo Zeus, el que amontona nubes, comienza a deshonrarme el primero, después de que me hizo su diligente esposa! Ahora engendró sin mi a Atenea, la de ojos de lechuza, que destaca entre todos los dioses bienaventurados, mientras que se quedó lisiado entre todos los dioses, tullido de los pies, mi hijo Hefesto, al que misma pari". (Himno Homérico a Apolo, 311-318). Hera no perdona que su esposo haya prescindido de ella para tamaña empresa, de matriz femenina. Ya aludimos a esa apropiación de Zeus de la maternidad y ahora aparece el conflicto que el gesto arroja. La propia Hera "dio a luz, sin trato amoroso estaba furiosa y enfadada con su esposo-, a Hefesto, que destaca entre todos los descendientes de Urano por la destreza de sus manos". (Hesíodo, Teogonía, 927930). 
Hera está furiosa, como suelen estar furiosas las esposas con sus esposos. Taimado y miserable son los adjetivos con que Hera descarga su cólera contra Zeus.

"¿Qué otra cosa se te va a ocurrir aún? ¿Cómo te atreviste a engendrar tú solo a Atenea, la de ojos de lechuza? ¿No habría podido parirla yo?". (Himno Homérico a Apolo, 322-324). La ira no se resuelve sólo con insultos en un mundo donde se miden poderes permanentemente. Hera anuncia un mal futuro para quien la ha desairado, ignorándola en más de un sentido: como mujer y como madre. El castigo es un hijo que no sea concebido en amoroso abrazo. Hera imita la aventura de Zeus, lo provoca con un gesto de idéntico registro y sola pare a Hefesto, según la versión hesiódica, sin que medie contacto amoroso alguno. Puja de poderes entre dos pesos pesados; duelo de desconocimientos y prescindencias que pone al Olimpo en clave agonística. El acto se acompaña con gesto y, vuelta hacia abajo, la diosa, atravesada por la furia, golpea el suelo, forma habitual de invocar a las divinidades ctónicas y exclama: ";Oídme ahora Tierra y ancho Cielo, allá en lo alto! ; $Y$ vosotros, Titanes, dioses que habitáis bajo tierra, en el gran Tártaro, de los cuales proceden hombres $y$ dioses! Escuchadme todos ahora y concededme un hijo sin el concurso de Zeus, en nada inferior a aquél en fuerza, sino tanto más poderoso que él cuanto lo es Zeus, cuya voz se oye a lo lejos, más que Crono". (Himno Homérico a Apolo, 334-339).

Más allá de sus peculiaridades, no podemos dejar de mencionar que, en el marco de la distribución racional de las funciones divinas, la antigua diosa ctónica tiene reservada la tutela del sexo femenino en general y, de ese modo, recibe honra como esposa, preside las bodas, la viudez, y, en última instancia,

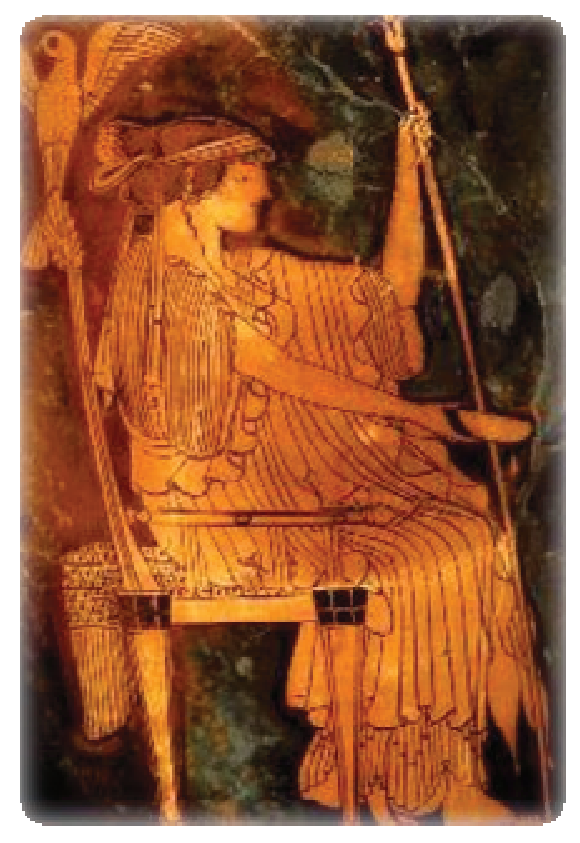
los estados fundamentales de la vida de la mujer.

De los tres hijos originarios de este conflictivo matrimonio, Ares resulta una figura de interés. Se trata de la fuerza destructiva de la guerra, divinidad sanguinaria y salvaje. Así lo describe el 
Himno Homérico: "Ares más que poderoso, abrumadora carga del carro de guerra, el de áureo yelmo, de intrépido corazón, portador de escudo, salvador de ciudades, revestido de bronce, brazo poderoso, infatigable, ardida lanza, valladar del Olimpo, padre de la Victoria, auxiliador de la Justicia, dictador para tus adversarios, guía de los varones más justos". (Himno Homérico a Ares, 1-7).

Como se ve, el Himno rescata en Ares valores positivos, que representan el más significativo valor cultural.

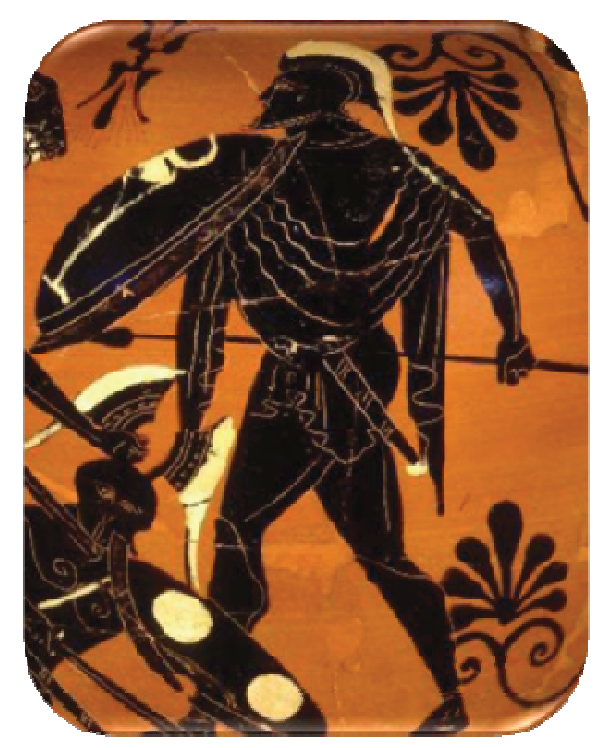

Hebe, la otra hija de Zeus y Hera, terminó siendo la esposa de Heracles, quien, al término de sus fatigosos trabajos, la hizo su venerable esposa en el nevado Olimpo, tal como refiere Hesíodo. (Teogonía, 953-955).

Para concluir este largo trabajo dedicado a los matrimonios reales, una breve referencia a otros hijos de Zeus y a los amores extramatrimoniales del Padre de hombres y dioses, esto es el contacto amoroso con mortales. Tres son las relaciones amorosas referidas en Teogonía. El primero se refiere al amor de una bella ninfa del Monte Cilene, en Arcadia, a escondidas de los Inmortales y los hombres mortales. "También con Zeus, la Atlántide Maya parió al ilustre Hermes, heraldo de los Inmortales, subiendo al sagrado lecho". (Hesíodo, Teogonía, 977-940).

El Himno Homérico nos devuelve esta primera pintura referida a su nacimiento: "Canta, Musa, a Hermes, hijo de Zeus y Maya, que tutela Cilene y Arcadia, pródiga en rebaños, raudo mensajero de los inmortales, al que parió Maya, la Ninfa de hermosos bucles, tras haberse unido en amor a Zeus, ella, la diosa venerable". (Himno Homérico a Hermes, 1-5). Se trata de un amor oculto, vivido en el interior de una gruta sombría, donde el Cronión solía unirse con la Ninfa en la oscuridad de la noche, mientras el sueño retenía a la temible Hera, que ignoraba el engaño. Cuando la décima luna se fijó en el cielo, "la Ninfa parió un niño versátil, de sutil ingenio, saqueador, ladrón de vacas, caudillo de 
sueños, espia de la noche, vigilante de las puertas, que rápidamente iba a realizar gloriosas gestas ante los ojos de los dioses inmortales". (Himno Homérico a Hermes, 14-18).

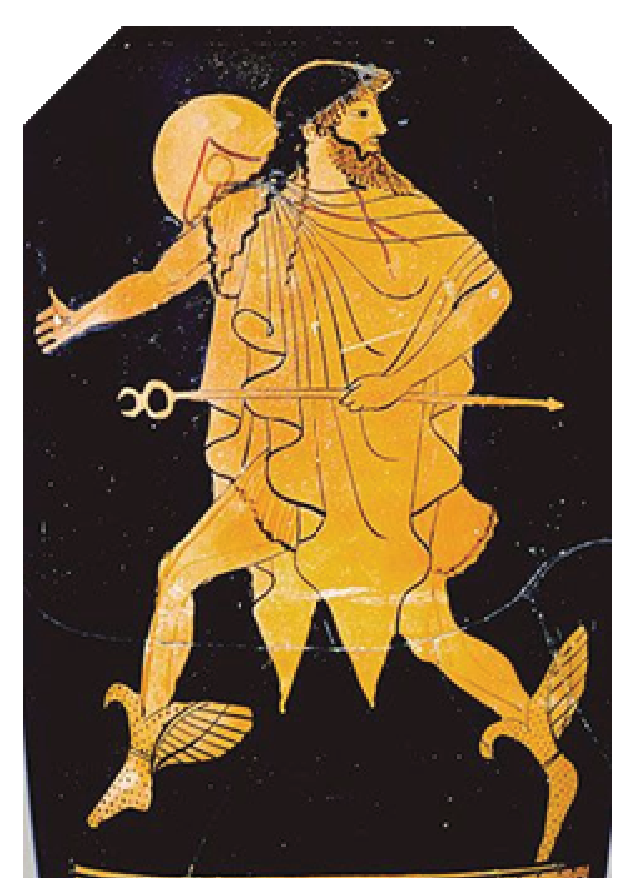

Figura importante a partir de su función de guía de los viajeros, símbolo de un dios-guía, por ende benévolo y de signo positivo, jamás deja de orientar a los que viajan, sujetos a los avatares del camino. Dios nómade que se niega a quedar territorializado a un espacio único, es el dios de los grandes caminos, astuto y movedizo, siempre dispuesto a la aventura.

Hay una unión por demás significativa en la economía general de los avatares amorosos olímpicos, a partir del fruto de esa relación. Nos referimos a Dioniso y su peculiar estatuto al interior de la arquitectura de los Inmortales. Refiere Hesíodo el contacto en estos términos: "Y la cadmea Sémele, igualmente en trato amoroso con él, dio a luz un ilustre hijo, el muy risueño Dioniso, un inmortal siendo ella mortal. Ahora ambos son dioses". (Hesíodo, Teogonía, 940-944).

La presencia de Dioniso es significativa no sólo por lo que el propio dios representa como divinidad compleja y paradojal, sino por las peculiaridades conyugales que su nacimiento desata, a partir de la cólera de Hera, conocedora de los amores extramatrimoniales de su esposo con Sémele, la Cadmea de hermoso rostro, hija del rey Cadmo. Nada puede enfurecer más a una esposa despechada que los amoríos con mortales, lo cual implica una mezcla heterogénea de elementos de distinto registro ontológico. Sémele es una mortal y ese dato amplía la furia de Hera, que desata sobre el niño toda clase de persecuciones y maldades.

Su presencia es celebrada con un himno dedicado a él, "el hijo de la gloriosisima Sémele, cómo apareció junto a la orilla del límpido mar en un promontorio avanzado, en la figura de un varón joven, en su primera adolescencia. 
Hermosos ondeaban en redor suyo los oscuros cabellos". (Himno Homérico a Dioniso, VII, 1-5).

El himno XXVI es rico en lo que hace a los matices de la infancia y crianza del niño, aparatado de su madre por la cólera de Hera, y el poder que puede desplegar en su cólera incontenible. Son las Ninfas, de hermosa cabellera, quienes lo crían tras haberlo recibido de su padre, el Soberano de hombres y dioses. "Cariñosamente lo cuidaron en los barrancos del Nisa, y él crecía por voluntad de su padre en una cueva fragante, pero contado entre los inmortales". (Himno Homérico a Dioniso, XXVI, 5-8). Ya criado, frecuenta los valles en compañía de sus nodrizas, coronado de hiedra y lauro.

Dioniso representa un dios paradojal en el marco de la religiosidad griega. Su riqueza semántica, en tanto múltiples daciones de sentidos, nos coloca ante un fenómeno de singulares resonancias antropológicas. En él se da una intersección de contrarios que se vuelven complementarios y constitutivos de la misma ambigüedad del dios. No se trata de contrarios que se

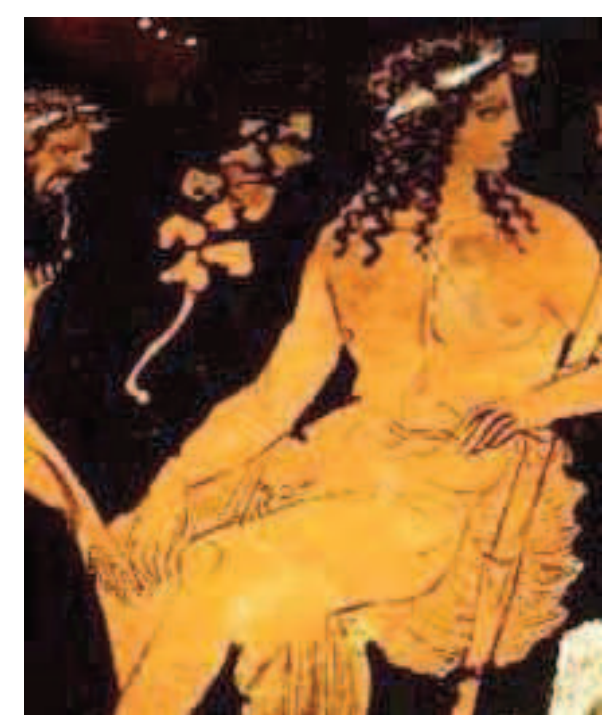
autoexcluyen, sino de pares propios de una lógica que los integra en una divinidad peculiar. Vida y muerte. Mismidad y Otredad. Marginalidad y centralidad. Oficialidad y no oficialidad parecen ser las aristas de una extraña figura de difícil cuadriculación en la regular clasificación de las palabras y las cosas. "Dioniso, el que atrapa brutalmente, el que hace tropezar a su presa, la arrastra a la locura, la muerte, la corrupción;

Dioniso, el de las vides maduras en un día, el de las fuentes de vino, de la bebida embriagadora y que da la efervescencia. ¿Este dios noble, no será, en fin, el mismo?".

Dioniso rompe todos los órdenes establecidos, genera una visión desde el margen, preanuncia la experiencia del borde y anticipa el umbral de la experiencia límite que aúna en un extraño festival la vida y la muerte, como las caras complementarias de un dispositivo áltero. La muerte se convierte en fiesta y la vida es el recuerdo de la celebración. 
Apenas una mínima pintura de un vástago complejo y apasionante, sin el cual no puede comprenderse la complejidad del universo olímpico.

Llegamos a un último hijo, no menor en su importancia y en su complejidad. Siguiendo siempre el relato hesiódico, el poeta lo pinta de este modo: "Alcmena parió al fornido Heracles en contacto amoroso con Zeus amontonador de nubes". (Hesíodo, Teogonía, 942-943). Heracles no es un dios, sino un héroe. El amor de Zeus por Alcmena, hija de Electrión, permite injertar la raza de los héroes, ya que el fruto del mismo es el más formidable de los héroes.

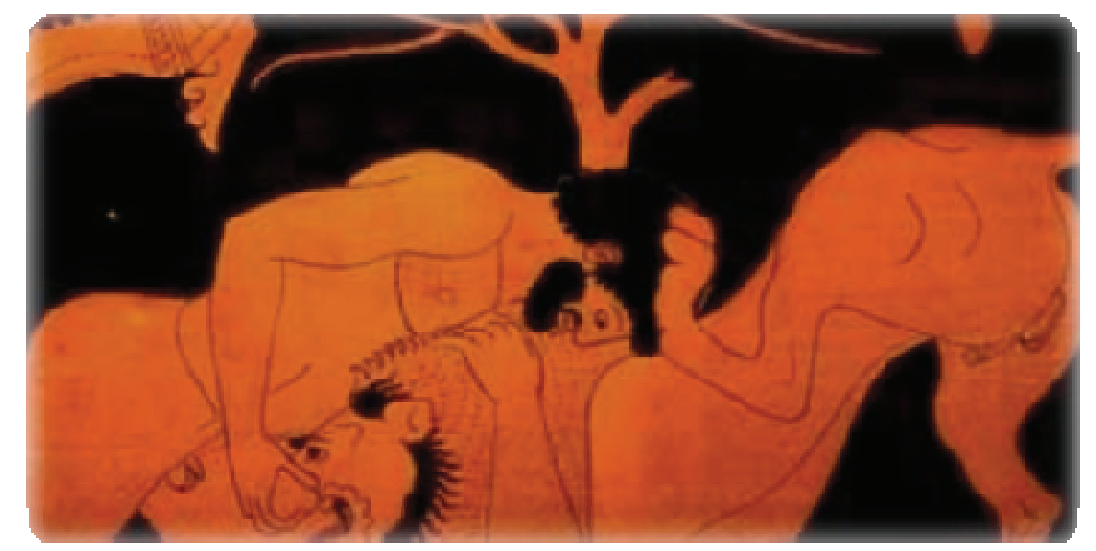

\section{Conclusiones}

El presente trabajo consistió en relevar problemáticamente la dimensión del matrimonio como topos político; el mismo aparece como un territorio ritualizado, que lo ubica en el juego agonístico de las relaciones de poder.

Hemos indagado las características de las uniones matrimoniales en el marco de la Grecia arcaica, recorriendo las marcas que el relato mítico hilvana. Sabemos que el mito como logos explicativo se torna un texto ineludible para inteligir las relaciones entre los distintos elementos constitutivos de una determinada trama discursiva.

Nos propusimos captar las relaciones de poder-saber, para lo cual nos instalamos en el suelo mítico como territorio emblemático de dación de sentido y nos animamos a desandar la huella de las uniones amorosas, para ver 
cómo ciertos matrimonios arquetípicos de la genealogía olímpica, nos permitió relevar los juegos de poder al interior de la práctica

Abordamos la esfera del matrimonio desde la perspectiva reproductiva, corazón palpitante de la cuestión matrimonial. Ese enclave fue testigo de los juegos vinculares, desplegados como juegos de poder.

Asimismo, nos propusimos rescatar la construcción de lo femenino y de lo masculino al interior de ese topos sobrecargado de consideraciones y valoraciones, que ponen de relieve su importancia como usina subjetivante, leída desde un horizonte dominado por las tensiones de poder.

Se trató de ver en cómo el matrimonio representa uno de los topoi naturales destinado a la consolidación y ficción cultural de lo femenino y de lo masculino, sobre todo de lo femenino, pero siempre en relación al papel de lo masculino al interior del dispositivo matrimonial.

Como siempre, toda institución que se consolide como un pilar del entramado histórico-cultural, el matrimonio, en este caso particular, hallará en el mito un espacio de discurso significativo. 


\section{REFERENCIAL DE IMAGENS}

\section{Índice de las ilustraciones según su orden de aparición}

\section{K19.1 THE BIRTH OF ATHENE}

Museum Collection: Antikenmuseen, Berlin, Germany

Catalogue Number: Berlin F1704

Beazley Archive Number: 310014

Ware: Attic Black Figure

Shape: Tyrrhenian amphora

Painter: Attributed to the Kyllenios Painter

Date: ca 570 - 560 BC

Period: Archaic

\section{T8.1 THEMIS \& AIGEUS}

Museum Collection: Antiken-sammlung, Berlin, Germany

Catalogue No.: Berlin F2538

Beazley Archive No.: 217214

Ware: Attic Red Figure

Shape: Kylix

Painter: Attr. to the Codrus Painter

Date: ca 430 BC

Period: High Classical

\section{K17.1 THE HORAI}

Museum Collection: Antikenmuseen, Berlin, Germany

Catalogue Number: Berlin F2278

Beazley Archive Number: 200108

Ware: Attic Red Figure

Shape: Kylix

Painter: Name vase of the Sosias Painter

Date: ca 500 BC

Period: Late Archaic

\section{K26.1 DEMETER \& PLOUTOS}

Museum Collection: The J. Paul Getty Museum, Malibu, California, USA Catalogue Number: Malibu 86.AE.680

Beazley Archive Number: N/A

Ware: Apulian Red Figure 
Shape: Loutrophoros

Painter: Attributed to Painter of Louvre MNB1148

Date: ca 350 - 340 BC

Period: Late Classical

\section{K20.1C MOUSA WITH BARBITON}

Museum Collection: Musée du Louvre, Paris, France

Catalogue Number: Louvre K570

Beazley Archive Number: N/A

Ware: Paestan Red Figure

Shape: Lekanis lid

Painter: Attributed to Asteas

Date: ca 360 - 340 BC

Period: Late Classical

\section{T14.3 APOLLON \& TITYOS}

Museum Collection: Musée du Louvre, Paris, France

Catalogue No.: Louvre G164

Beazley Archive No.: 205657

Ware: Attic Red Figure

Shape: Krater

Painter: Attributed to the Aegisthus Painter

Date: ca 470 - 465 BC

Period: Early Classical

\section{K5.2 APOLLON}

Museum Collection: Delphi Archaeological Museum, Delphi, Greece Catalogue Number: Delphi 8140

Beazley Archive Number: 5522

Ware: Attic Red Figure (White Ground)

Shape: Kylix B

Painter: Attributed to Euphronios or to Manner of Pistoxenos Painter Date: ca 470 BC

Period: Classical 


\section{K6.2 ARTEMIS}

Museum Collection: State Hermitage Museum,

St Petersburg, Russia

Catalogue Number: St Petersburg B2365

Beazley Archive Number: 206365

Ware: Attic Red Figure (White Ground)

Shape: Lekythos

Painter: Attributed to the Pan Painter

Date: ca 500 - 459 BC

Period: Late Archaic / Early Classical

\section{K4.1 HERA}

Museum Collection: Museum of Art, Rhode Island School of Design, New York City, USA

Catalogue Number: RISD 25.078

Beazley Archive Number: 204109

Ware: Attic Red Figure

Shape: Lekythos

Painter: Attributed to the Brygos Painter

Date: ca 500 - 475 BC

Period: Late Archaic

\section{K9.6 HERAKLES \& KYKNOS}

Museum Collection: Worcester Art Museum, Massachusetts, USA

Catalogue No.: Worcester 1966.63

Beazley Archive No.: 1986

Ware: Attic Black Figure

Shape: Neck amphora

Painter: Attributed to the Leagros Group

Date: ca 515 - 500 BC

Period: Late Archaic

\section{K11.11 HERMES}

Museum Collection: Metropolitan Museum, New York City, USA

Catalogue Number: New York 25.78.2

Beazley Archive Number: 203182

Ware: Attic Red Figure 
Shape: Lekythos

Painter: Attributed to the Tithonus Painter

Date: ca 500 - 450 BC

Period: Early Classical

\section{K12.1 DIONYSOS}

Museum Collection: Harvard University Art Museums, Cambridge, Massachusetts, USA

Catalogue Number: Harvard 1960.347

Beazley Archive Number: 217539

Ware: Attic Red Figure

Shape: Hydria-kalpis

Painter: Attributed to the Class of Brussels A3099

Date: ca 410 - 400 BC

Period: Classical

\section{M19.6 HERAKLES \& THE NEMEAN LION}

Museum Collection: University Museum, University of Pennsylvania, Philadelphia, Pennsylvania, USA

Catalogue Number: Philadelphia L-64-185

Beazley Archive Number: 201712

Ware: Attic Red Figure

Shape: Stamnos

Painter: Attributed to the Kleophrades Painter

Date: ca 490 BC

Period: Late Archaic 